- La última casa a la izquierda.
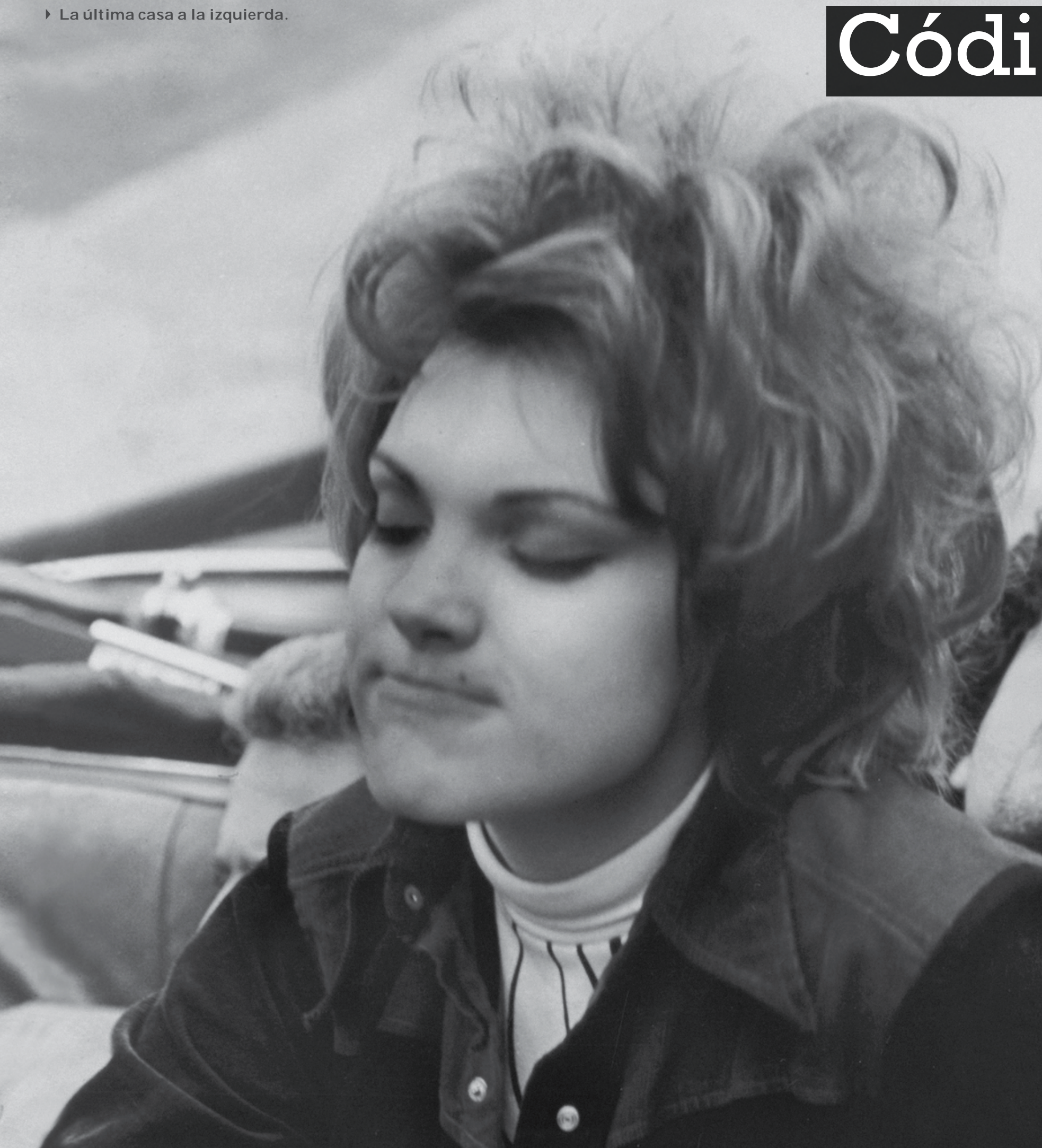

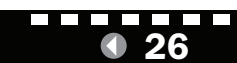

26 


\section{gos prohibidos:}

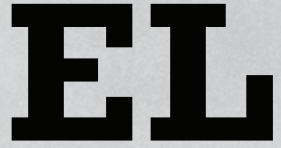

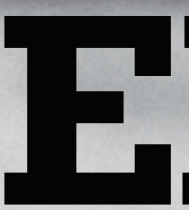
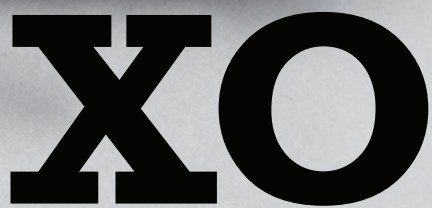
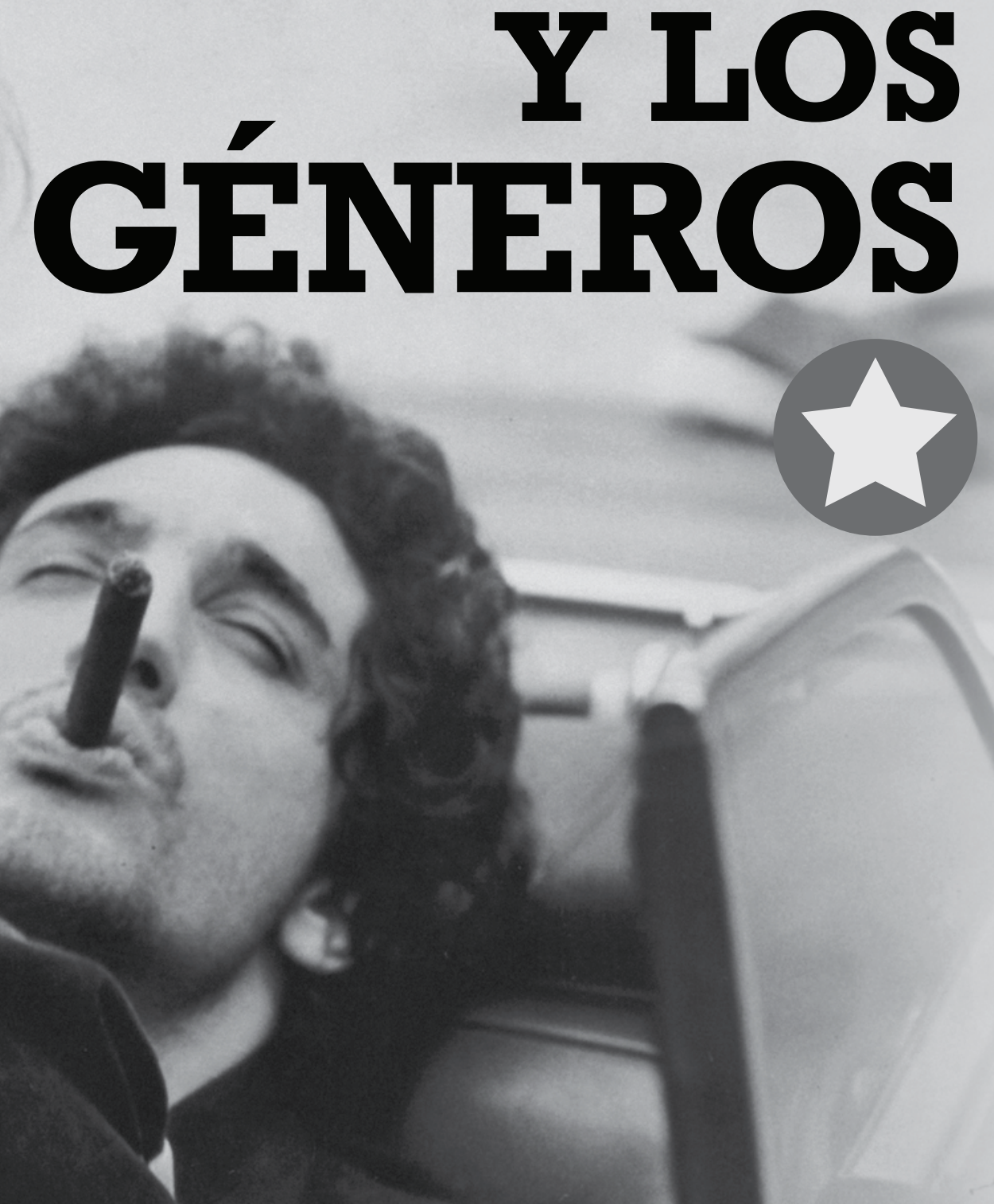

\section{Eros y tánatos: el cine de terror}

Juan Armesto

Desde las grotescas orgías demoniacas pintadas por El Bosco, pasando por las tenebrosas presencias lascivas de Drácula y Mr. Hyde, que la literatura romántica inmortalizó, y desembocando finalmente en nuestros queridos asesinos seriales Michael Myers o Freddy Kruger, las historias de lo horrendo han sido siempre un vehículo de sensaciones y representaciones (¿represiones?) de índole más bien erótico.

¿Porqué? Bien lo explicaba Sigmund Freud al decir que los instintos gobiernan la vida de los seres humanos, y aquellos están sujetos a las pulsiones de vida (eróticas) y las de muerte (tanáticas) que desarrollan una constantelucha entre explayarsey contenerse, que finalmente constituye la esfera social.

El uso generalizado de recursos estilísticos provenientes del gore (películas enfocadas en la muerte y la violencia al detalle) en el cine de terror, su visceralidad y la demostración de un cuerpo frágil empatan con la aparición de una visión inédita y detallada de orificios y secciones privados del cuerpo, agrupados bajo el género 
pornográfico gonzo, el cual aprovecha la temática casera y de video amateur para darle mayor participación al espectador. Una constante que se deja percibir cada vez más en el cine de terror actual y dela cual Chacho León ya noshailustrado en un número anterior ("El ojo invisible: la cámara-personaje en las ficciones de horror con soporte documental", Ventana Indiscreta 5).

Las películas de asesinos o slashers ha funcionado como levadura para nutrir estas dimensiones visuales. Dotadas de temáticas extremas, lograron inmortalizar y desvelar los crímenes de psicópatas fetichistas. Pensemos en la primera escena de Halloween (J ohn Carpenter, 1978) o en las coreográficas muertes de Suspiria (Dario Argento, 1977) y en las atroces violaciones de La última casa a la izquierda (Wes Craven, 1972), cuyo irremediable desarrollo se deja ver en las recientes secuelas de Juego macabro (James Wan, 2004) u Hostal (Eli Roth, 2005).

Otra recurrencia es el componente grotesco que acarrea este juego de penetración y disección del cuerpo. Brian Yuzna nos lo muestra en Society (1989), una película donde los términos festín orgiástico macabro y visce$\mathrm{ral}$ tienen total equivalencia visual. $\mathrm{O}$ la fantástica escena del sueño en Dead Ringers (David Cronenberg, 1988), en la que Claire Niveau (Geneviève Bujold) muerde el trozo de carne que une a los hermanos Manttle (interpretados por J eremy Irons).

Pero si de erotismo y cine de terror contemporáneo se trata nadie mejor - o en mayor cantidad por lo menospara graficarlo que Jesús Franco. El prolífico director español dejó rebalsar su abundante imaginación sobre los clásicos con un desparpajo único (falleció el pasado 2 de abril). Un genio del cine de explotación que jamás se prohibió nada y a quien el terrory el erotismo le corrían por las venas.

Así son las cosas en la actualidad, el vínculo perenne entre sexo y violencia, entre terror y erotismo, ya no es más un tema sorprendente o un descubrimiento académico: es una realidad fáctica que se explota con mayor ahínco y premura que nunca: zombies homosexuales en Otto; or, Up whit dead peoplede Bruce La Bruce(2008); vampiras lesbianas en Vampyros lesbos (Jess Franco, 1971); o transexuales mecánicos en Tetsuo: Theiron man de Shinya Tsukamoto (1989) conforman la parafernalia de aristas sexuales que se desprenden directamente o no del cine de terror contemporáneo.

\section{Sexo y conservadurismo:} la comedia

Rodrigo Bedoya

"Nosotros te rascamos la espalda, y después tú nos rascas la tuya". "Sí, pero lo raro de mi espalda es que está ubicada en mi pija”. Esa última frase la dice Seth (Jonah Hill), uno de los protagonistas de Supercool, una de las mejores comedias de los últimos años. Y una en la que el sexo tiene un papel preponderante: en el diálogo, en las acciones, en las actitudes.

Y si el cine norteamericano está pasando por una época especialmente pacata, pues la comedia está para transgredir. Siempre, claro está, con la concesión del final feliz, que bien manejada puede ser una fresca bocanada de aire de cinismo. Ahí están los hermanos Farrelly, que han tratado de darle al modelo de la comedia romántica un toque de incorrección política basada en lo sexual. Como el esperma de Ben Stiller en el pelo de Cameron Diaz, las tetas de Lin Shaye en Loco por Mary, el vibrador de Jim Carrey en Irene, yo y mi otro yo, o el sexo oral del personaje de Jason Sudeikis en Pase libre. Los Farrelly nuncalehan tenido miedoala escatología, a usar el sexo como motor del humor en situaciones precisas.

Judd Apatow es otro cineasta que utiliza la comedia romántica para hablardesexo pero deunamaneramucho más sutil. Un encuentro casual entre la hermosa Katherine Heigl y el irresponsable Seth Rogen en Ligeramente embarazada hace que ella quede en cinta. La noche furtiva se convierte en el motor de una serie de responsabilidades que el hombre deberá asumir. Lo mismo le ocurre a Steve Carrell en Virgen a los 40: su personaje no ha tenido sexo, y lo que viene es justamente todo un ritual masculino para que pueda, finalmente, acostarse con alguien.

El cinedeApatow utiliza varios miedos sexuales masculinos modernos, como el embarazo indeseado o la necesidad de perder la sexualidad, pero no hace películas escatológicas, sino

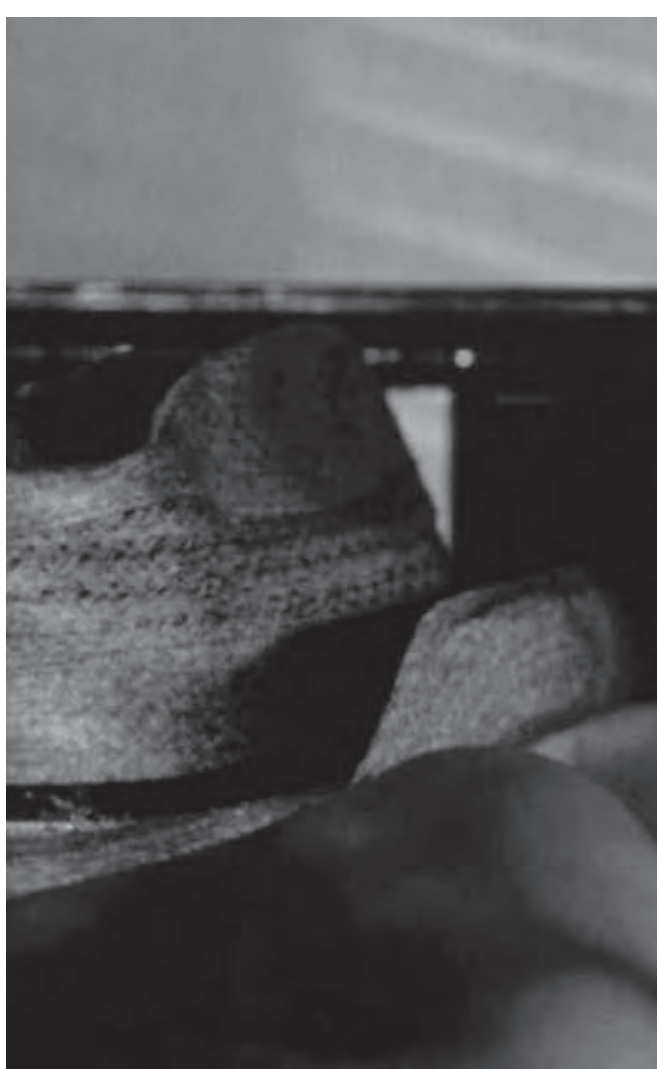

\ La generación maldita.

más bien rituales, donde los personajes deben atravesar un proceso para conseguir su objetivo, un proceso que resulta complicado. Por eso, muchas veces uno no sabe si reír o llorar ante las situaciones que vemos. El sexo es divertido, pero también melancólico.

$\mathrm{Y}$, por supuesto, otra gran vertiente es la comedia juvenil. El sexo siempre ha estado ligado a este género, que fue, de alguna manera, revitalizado por American pie: tu primera vez. ¿Qué resulta divertido? Pues ver a Jim (Jason Biggs) fracasar de las maneras más absurdas posibles en sus intentos de tener sexo. Ya sea teniendo al frente las tetas de Shannon Elizabeth o un pie de manzana, el personaje no la hace nunca. Y cuando la hace, pues la hace con la máslorna, queresulta ser la más kinky. Si se habla mucho de que ser nerd ahora es cool, pues American pie lo prefiguró de manera muy clara.

Pero la gran comedia juvenil de la generación del 2000 es Supercool, que también trata de un par de lornas que hacen lo que pueden con tal de tener sexo. Perola sexualidad, más quenada, se expresa en los diálogos, filosos como pocos, que capturan muy bien lo que los buenos amigos muchas veces dicen 


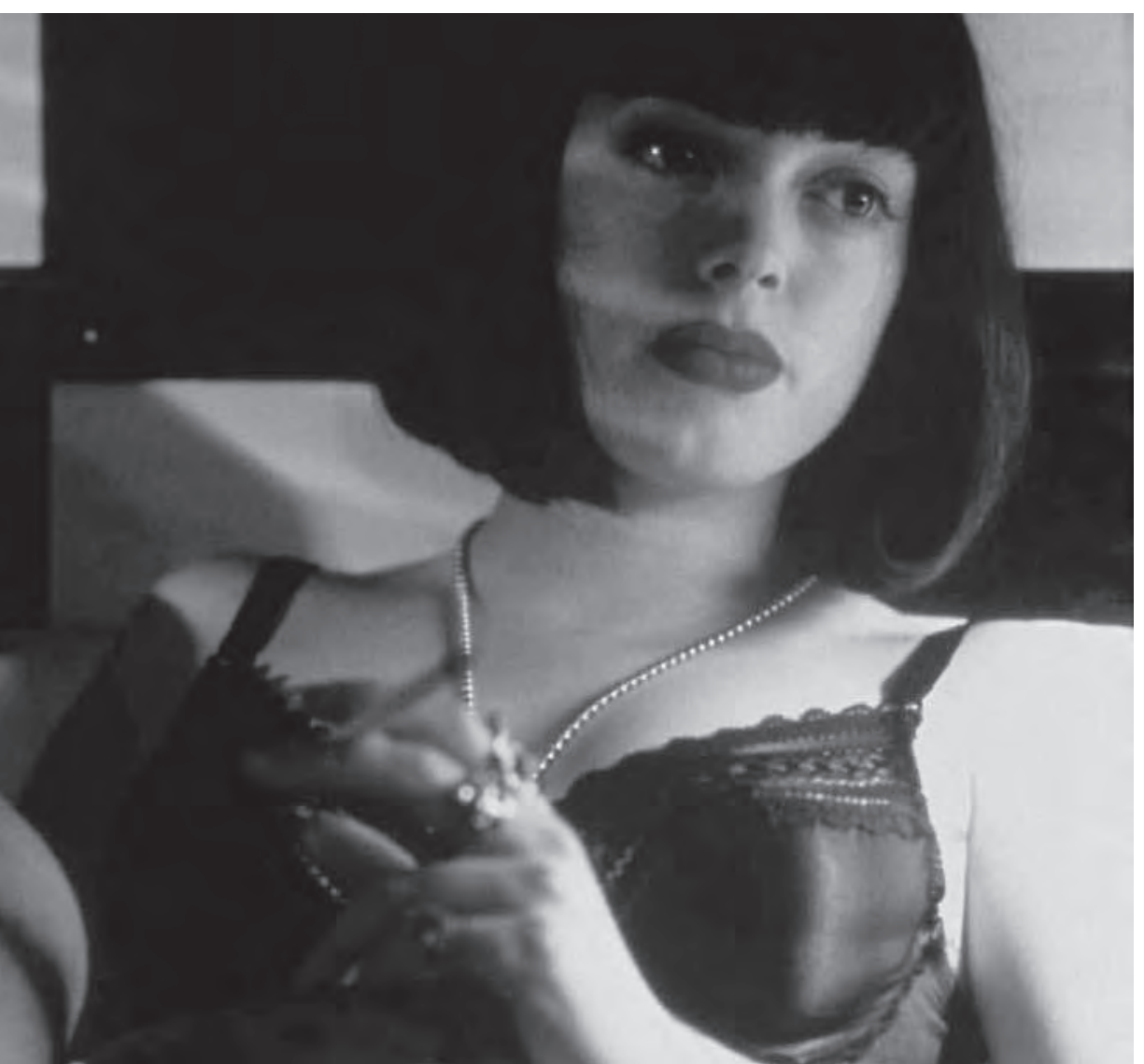

al hablar de una mujer. Y ahí también está McLovin, la representación del lorna del colegio más exquisita que uno recuerde.

En Supercool, el sexo no se ve, pero seescucha. Y, también, sedibuja, como lo demuestran las representaciones de pijas que dibuja el gran Seth. El actor en sí, como suele ocurrir, resulta frustrado. Porque así son los perdedores. Y ser perdedor, ahora, es ser cool.

\section{Erotismo en tránsito:} las road movies

Mónica Delgado

En Weekend, deJ ean-Luc Godard, Corinne (Mireille Darc) y Roland (Jean Yanne) son una pareja de esposos de clase media que emprenden un viaje por la carretera, hacia la Francia rural y estrambótica, en una metáfora antiburguesa y de cariz marxista. En una escena inicial hay una clave: Corinne narra historias para estimular sexualmente a su esposo, que van desde encuentros lésbicos hasta reminiscencias a Georges Batailley su Historia del ojo. La escena está filmada para que vea- algunas road movies, sobre todo en aquellas donde se viaja de a dos, a la fuerza, por necesidad o por placer. Allí están películas desdeBonniey Clydede Arthur Penn o La generación maldita de Gregg Araki, pasando por Thelma y Louise o Romance salvaje delos Scott. Mujeres al volante o que lo acompañan sin sutilezas, al grano, para escapar con el botín en mano pero donde el sexo es inevitable, dentro del auto o en un motel de carretera cercano, asumiendo sin querer un rol pasivo, como, por ejemplo, en Asesinos por naturaleza, donde Micky tiene que salvar a Mallory de la picadura de serpiente, o en Badlands, donde Holly es la razón de la huida pero no la incita. Así como se define en la trama de las road movies el rol pasivo, también están los paradigmas de la niña (la desfloración de Sissy Spacek/Holly) o la puta (Rose McGowan en La generación maldita), donde existe un aprendizaje de liberación o de recuperación del orden.

Quizás la road movie emblemática donde el manejo del erotismo como catalizador de la trama y de crecimiento o ruina de los personajes sea la mexicana Y tu mamá también, de Alfonso Cuarón, donde una Maribel Verdú es el objeto del deseo de dos adolescentes en viaje de aprendizaje sexual y amoroso. El viaje como sinónimo de auscultación y pérdida delos cuerpos, puesto que al llegar al destino, el cineasta muestra la disolución de la amistad, pero también la ausencia repentina del "objeto" deseado. Acaba el viaje y el cuerpo deseado desaparece con él. nado, y ha dejado algo claro, un cuerpo solo que devora a otro. Como cuando Bataille en El erotismo se refiere al canibalismo sagrado: "ejemplo elemental de la prohibición creadora de deseo; que sea prohibida no le da otro sabor a la carne, pero ésa es la razón por la que el "piadoso" caníbal la consume..... Comerseal marido como acto extremo de deseo saciado y de prohibición, y que Godard coloca como alegoría social de la implicancia del matrimonio dentro de un sistema burgués, se vuelve el deseo reprimido que termina en la anulación del otro como consecuencia de la alienación, y todo dentro de una ruta y en un viaje sobre ruedas. Una lectura delo erótico.

Pero Weekend es un ejemplo extremo e irrepetible de cómo el erotismo en sí es un motivo indispensable para

\section{Fantasías de otro mundo: la ciencia ficción}

Miguel Mejía Salas

En 1968, Roger Vadim dirigió una ingenua aventura espacial de la serie B que habría quedado muy pronto en el olvido si no fuera por el énfasis que puso en un aspecto poco frecuente en el cine de ciencia ficción: el comportamiento sexual. Barbarella, el filme en cuestión, se vale del mencionado género cinematográfico para mostrar sin prejuicio algunos tópicos de la cultura de los años sesenta, como las drogas y la sexualidad, más aún, haciéndolo desde el punto de vista femenino. Desde el espectacular striptease de Jane 
Fonda en los créditos iniciales, la película mantiene una carga erótica constante, tanto en los diálogos como en los atuendos y la recreación de un mundo fantástico-espacial que derrocha sensualidad, aderezada con fino humor e ironía.

La ciencia ficción no es un género que trabaje la sexualidad como tema central. Sin embargo, se vale de ciertos elementos para elevar un poco la "temperatura" de las audiencias, disparando certeros flechazos a la libido del espectador, priorizando lo sugerente frente a lo explícito u otorgando breves dosis de carnalidad a escenarios metálicos, historias apocalípticas o laboratorios asépticos.

El diseño de vestuario es el recurso más habitual. Recordadas heroínas se han impregnado en el imaginario popular, no tanto por sus valerosas acciones, sino más bien por las provocativas

MELODRAMA Y EROTISMO EN EL CINE DE HOY

¿Se puede hablar del género del melodrama en el cine contemporáneo? ¿Las películas con rasgos melodramáticos trabajan el erotismo? Isaac León Frías y Ricardo Bedoya conversan al respecto.

Isaac León Frías: Como una impresión general, un poco más ampliay abarcadora, creo que directores como Wong Kar-wai o Pedro Almodóvar muestran versiones muy estilizadas, en algunos casos fuertemente manieristas, deestructuras melodramáticas, que aparecen re-significadas. Entonces, es el melodrama y al mismo tiempo no lo es. Tanto así que es muy difícil poder hablar en rigor de que estamos ante un melodrama. Como ya ocurría en el caso de Fassbinder, que es tal vez uno de los más interesantes en el cine europeo en el periodo en que él tuvo vigencia. Planteándolo casi como una hipótesis, yo diría que Fassbinder es tal vez el último en el cual hay un proyecto estético más orgánicamente ligado al género. En los últimos tiempos mi impresión es que el melodrama está más desencajado. El caso de Almodóvar es uno de los más interesantes porque está muy atravesado

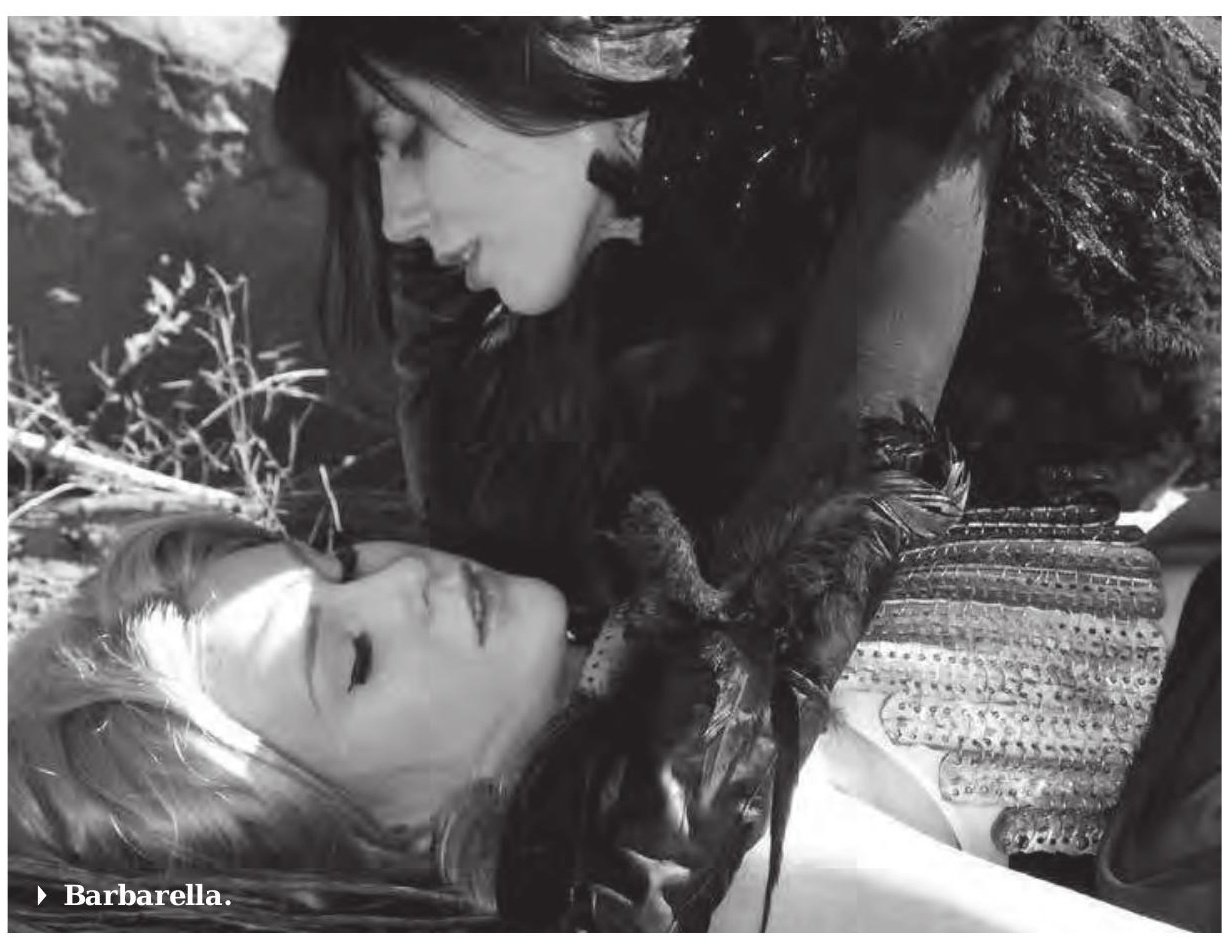

por otras matrices genéricas. Lo que hacen muchos de los cineastas contemporáneos es recoger algunos delos motivos del melodrama y los llevan, como sucede en Con ánimo de amar, casi a una suerte de desecamiento, es una pareja en la que prácticamente el vínculo está bloqueado. En definitiva, creo que estamos frente a unas propuestas distintas.

Ricardo Bedoya: El melodrama suele ser muy pudoroso al tratar la sexualidad, porque lo que le interesa al género son las consecuencias que trae una relación erótica o sexual. Es decir, el drama se desencadena luego de esa relación. En el melodrama, el erotismo suele ser un agente dramático. Cuando se piensa en los grandes melodramas, aparecen las imágenes de personajes femeninos (los de Mizoguchi, los de Michael Curtiz, los del melodrama mexicano) padeciendo por una relación del pasado que las estigmatizó. Son víctimas de su sexualidad y de personajes masculinos que poseen una doble moral.

ILF: En lo que se refiere directamente al tema del erotismo, la impresión que yo tengo es que hay una cierta crisis de la manifestación erótica, que tiene que ver también con el hecho de que estemos ante vínculos que son más elusivos o que, en otros casos, pueden ser perversos, como en Almodóvar en su última película, La piel que habito. Entonces, hay como una suerte de vacío, de privación, casi de imposibilidad.

RB: Hay una escena de violación en La piel que habito. Tigrinho, ese personaje extravagante, vestido como animal, es el autor de la violación, que se parece a una escena de Kika.

ILF: Claro, y está sugerido también el bestialismo ahí. Pero no es pues "erotismo". Es más una escena sexual antierótica, porque en realidad es tosca. Incluso, viéndolo en la obra de Almodóvar, qué distinto es si uno se remite a los tiempos de La ley del deseo, por más que tuviera una carga perturbadora.

RB: Pero hay una dimensión erótica muy fuerte en Los abrazos rotos. También en La piel que habito. Erotismo y deseo de absoluto. La necesidad de recrear a la mujer para conseguir una figura ideal, como en Vértigo o en Los ojos sin rostro. Es un erotismo turbio, con elementos góticos, casi fantásticos. En Almodóvar, el erotismo se infiltra en historias que remiten a géneros diversos. No hay un melodrama ortodoxo. En Hable con ella la figura de la pe- 
prendas que lucen en pantalla. Una poco agraciada Carrie Fisher protagonizó junto a un lujurioso monstruo espacial (Jabba the Hutt), una escena en la que su vestuario de esclava resaltó una sensualidad contenida a lo largo dela saga de La guerra delas galaxias (La guerra de las galaxias: episodio VI - El regreso del Jedi, Richard Marquand, 1983). Ornella Muti vistió a la princesa Aura (Flash Gordon, Mike Hodges, 1980) como contrapunto fatale de una modosita Dale Arden (interpretada por la olvidada Melody Anderson). Un poco más atrevidas lucen Milla Jovovich (El quinto elemento, Luc Besson, 1997) y Charlize Theron (Æon Flux, Karyn Kusama, 2005). Y como para todos los gustos hay, no podemos dejar de mencionar los diseños homoeróticos que dieron mucho que hablar en la franquicia del hombre murciélago (Batman forever, J oel Schumacher, 1995; Batman

netración en la mujer convertida en objeto se desplaza a la simbología del amante menguante. La sexualidad se convierte en artificio. Todo es figurado y simbólico; es convención.

ILF: Se trata de un erotismo mucho más retorcido, tortuoso. Es manierista, tiene mucho que ver la opción estilística. Lo que pasa, también, con Wong Kar-wai y su película americana Buscando un amor (My blueberry nights) que es tan manierista. Entonces, el punto de partida expresivo, estético, la plataforma visual del director es tan fuerte que atraviesa el relato. En el melodrama, en general, hay una desarticulación pasional en el punto de partida, evidentemente, por más que todo parezca muy tranquilo y muy quieto. Pero en estos casos yo diría que esa desarticulación es mucho más tortuosa y no hay nada ni tranquilo ni quieto.

RB: O es un erotismo culposo. En Los puentes de Madison, de Clint Eastwood, que tiene una factura más clásica, el erotismo trajo dolor y separación. La sexualidad se revela en las cartas que revisan los hijos del personaje de Meryl Streep.

ILF: Yocreoqueen LospuentesdeMadison hay un pie en la tradición clásica mucho más claro que en otros casos.
\& Robin, Joel Schumacher, 1997).

Enladécada delosnoventa, una película deregularéxito searriesgóa poner el sexo como ejecentral del argumento. Especies (1995), de Roger Donaldson, marca el debut cinematográfico de una despampanante y turbadora Natasha Henstridge, quien encarna a una criatura mitad humana, mitad alienígena, cuyo único deseo es copular con un macho humano que satisfaga su deseo de reproducirse a toda costa. Senos a discreción para beneplácito de la audiencia masculina. También por esos años, Paul Verhoeven dirigió Starship troopers (1997), filme que no tuvo muy buena acogida por parte de la crítica, pero cuyo casting parecía sacado de un catálogo de belleza, con chicos y jovencitas salidos de las canteras de la televisión, que poco sabían de actuación cinematográfica pero lucían muy apetecibles en la gran pantalla.

Aquí sí creo que es mucho más notorio ese afán de relectura del melodrama. El proyecto estético de Almodóvar es mucho más complejo. Hay este cruce de géneros. La piel que habito es una película que tiene elementos de horror, que remite a Los ojos sin rostro y al mad doctor de esa película. Está este elemento mucho más fantástico, es una película situada en un universo muy fronterizo en el que se suman los elementos de melodrama. En cambio, en Los puentes de Madison sí hay una ligazón mayor.

RB: En el caso de Wong Kar-wai, en Con ánimo de amar, el erotismo es una simulación, un teatro. Las pasiones se representan y se viven de modo vicario, a través de las relaciones que mantienen los cónyuges de los protagonistas. Es una dimensión reprimida. Los enamorados están siempre acosados por el ruido de los otros, ese entorno que parece vigilarlos en la pensión o en cualquier lado. Y ellos convierten su atracción mutua en un juego de acercamientos que el director filma como un ritual de roces y aproximaciones, que se desaceleran o se contemplan a través de ventanas, marcos, encuadres al interior de otros encuadres. Es un erotismo ritualizado y voyerista.
El uso de la realidad virtual ha sido pretexto también para recurrir a emociones y fantasías que, en mayor o menor grado, todos quisiéramos experimentar. El sexo virtual o cybersex fue explorado en El hombre del jardín (Brett Leonard, 1992) y Días extraños (Kathryn Bigelow, 1995), presentando escenas que con seguridad han ocasionado algunas sudoraciones y reacomodos en las butacas.

Aunque se trata de un breve recorrido, que no ha querido transitar por aquellas producciones que solo utilizan el género como un pretexto para presentar productos que ya pertenecen a los terrenos de la pornografía soft o hardcore, con total seguridad el cine de ciencia ficción serio nos seguirá obsequiando situaciones, ambientes y personajes que, sin duda alguna, estimularán nuestras retinas.. y algo más.

ILF: Incluso en el contacto o cercanía de ellos. En Con ánimo de amar siempre vemos el vínculo presencial de los dos personajes que sugiere esa pulsión que está ahí latente. Lo que pasa es que lo erótico está más en lo sugerido que en lo directamente representado. Lars Von Trier ha trabajado el melodrama también. En Rompiendo las olas hay componentes eróticos...

RB: Hay una secuencia erótica muy lograda en Rompiendo las olas, cuando ella descubre el cuerpo desnudo del marido. Luego, la sexualidad está marcada por la violencia.

ILF: El componente de autohumillación sexual termina imponiéndose. Ahora, en el caso del cine de Ripstein, digamos que ahí sí se recupera de otro modo si no la tradición sí las huellas de un pasado melodramático en el cine mexicano.

RB: En el cine de Ripstein son melodramas de crueldad. Los personajes se humillan y al director no le interesa la condición o la naturaleza de la sexualidad sino el registro de la caída. En Profundo carmesí, por ejemplo, los amantes se abisman cada vez más. La sexualidad es un infierno; está despojada de cualquier posibilidad de goce. 